\title{
COMBINAÇÃO DE LEIS NO ÂMBITO DO DIREITO PENAL: FATOR DE INSEGURANÇA JURÍDICA.
}

VICK MATURE AGLANTZAKIS 


\title{
COMBINAÇÃO DE LEIS NO ÂMBITO DO DIREITO PENAL: FATOR DE INSEGURANÇA JURÍDICA.
}

\author{
Vick Mature Aglantzakis ${ }^{1}$
}

\section{RESUMO}

$\mathrm{O}$ presente texto tem a missão de demonstrar a possibilidade ou impossibilidade jurídica de combinação de leis no âmbito do Direito Penal. Cuida-se de um estudo crítico embasado na doutrina penal e na interpretação dos Tribunais Pátrios. O artigo jurídico demonstra que a possibilidade do juiz criar uma lei, ainda que para beneficiar, poderá comprometer os parâmetros axiológicos do princípio da segurança jurídica É indispensável que a lei (ato legislativo) seja emanada do poder competente, sem o que não traz consigo força coercitiva e fere o princípio da segurança jurídica, independência dos poderes, bem como a igualdade jurídica.

\section{ABSTRACT}

This text has the mission to demonstrate the possibility or impossibility of legal combination of laws under the Criminal Law. Caring is a critical study grounded in doctrine and interpretation of criminal courts Natives. The article demonstrates the legal issue as a form of hermeneutics that could compromise the parameters of the principle of legal axiological.A safety law is a legal precept in writing, issued by the competent power. It is essential that the law (legislative act) is issued by the competent power, without which it brings with coercive force and violates the principle of legal security and independence of powers, and legal equality.

\section{"NA OBRIGAÇÃO DE DECIDIR SEMPRE, NÃO SE COMPREENDE A PRERROGATIVA DO JUIZ -DE SUBSTITUIR O LEGISLADOR EM PARTE, COMO PRETENDE A ESCOLA DE KANTOROWISC, "2}

O Superior Tribunal de Justiça reascendeu velha polêmica no que diz respeito à possibilidade ou não de um magistrado combinar

\footnotetext{
'Bacharel em Direito pela UFRR e Pós-Graduado em Direito Civil e Processual Civil pela Universidade Estácio de Sá, Ex-professor voluntário na Universidade Federal de Roraima UFRR, nas cadeiras de Direito Civil I e Processo Penal II. Secretário Parlamentar na Câmara dos Deputados.e-mail: vickmature@gmail.com

${ }^{2}$ MAXIMILIANO, Carlos. Hermenêutica e aplicação do direito. São Paulo: Forense, 1994. p. 52.
} 
duas leis penais, gerando uma terceira (Lex Tertius), para favorecer o réu, quando da aplicação da sentença.

Sintetizando o tema, Assis Toledo explica:

Questão polêmica é a de saber se, na determinação da lei mais benigna aplicável, pode o juiz tomar os preceitos ou os critérios mais favoráveis da lei anterior $e$, ao mesmo tempo, os da lei posterior, combiná-los e aplicá-los ao caso concreto, de modo a extrair o máximo beneficio resultante da aplicação conjunta só dos aspectos mais favoráveis de duas leis. ${ }^{3}$

A lei 11.343/06, que revogou a lei $6368 / 76$, também conhecida como Lei de Tóxicos, em seu art. $33, \S 4^{\circ}$, tem uma parte que beneficia o réu e o art. 12, da lei revogada, possui parte que é melhor para o réu. Para melhor compreensão, transcrevo os mencionados dispositivos legais:

$\S 4^{\circ}$ Nos delitos definidos no caput e no $\S 1^{\circ}$ deste artigo, as penas poderão ser reduzidas de um sexto a dois terços, vedada a conversão em penas restritivas de direito, desde que o agente seja primário, de bons antecedentes, não se dedique às atividades criminosas nem integre organização criminosa.

Saliente-se que a cabeça do artigo fixou pena mais severa (reclusão de 5 a 15 anos e pagamento de 500 a 1.500 dias-multa), diversamente da lei anterior que possuía uma pena mais branda, contudo sem os benefícios do $\S 4^{\circ}$, art.33, da lei 11.343/06.

Art.12, da lei 6368/76 Importar ou exportar, remeter, preparar, produzir, fabricar, adquirir, vender, expor à venda ou oferecer, fornecer, ainda que gratuitamente, ter em depósito, transportar, trazer consigo, guardar, prescrever, ministrar ou entregar, de qualquer forma, a consumo substância entorpecente ou que determine dependência física ou psíquica, sem autorização ou em desacordo com determinação legal regulamentar. Penareclusão de 3 a 15 anos, e pagamento de 50 a 360 diasmulta.

É imperioso salientar que a Constituição Federal definiu em seu art. $2^{\circ}$, quais são os poderes ou funções que compõem a federação

${ }^{3}$ TOLEDO, Francisco de Assis. Princípios básicos de direito penal. 4. ed. São Paulo: Saraiva,1991.p. 36 
brasileira: executiva, legislativa e judiciária.

Ao ser institucionalizado o Superior Tribunal de Justiça, conforme preceituado no art. 105, a Constituição Federal, atribuiu a este órgão jurisdicional dar a lei federal infraconstitucional uniformização de interpretação para se evitar a perplexidade entre julgados distintos sobre a mesma matéria e fatos levados ao judiciário.

Contudo, entre o que pretende a Carta Magna e a realidade há uma distância enorme. O próprio Tribunal da Cidadania, ainda não pacificou entendimento sobre as disposições acima referidas. Assim, não aceita a combinação de leis a $5^{\mathrm{a}}$ turma. Porém, a $6^{\mathrm{a}}$ turma, aplica a combinação de leis no caso envolvendo tóxicos e as disposições retro mencionadas.

A grande questão que surge é no que se refere ao remédio judicial proposto no Superior Tribunal de Justiça. Torna-se uma verdadeira loteria para o réu.

Dependendo da turma do STJ em que seja distribuído eventual Recurso Especial ou Habeas Corpus, o indivíduo será ou não beneficiado, com a aplicação da combinação das leis 11343/06 e 6368/76. E como explicar isso a um leigo? Impossível! Se as decisões são frutos de um ato de vontade e de inteligência conjugados, os efeitos decorrentes das disparidades nos acórdãos sobre o tema, afrontam violentamente os Direitos Fundamentais, consistindo em verdadeira negativa dos princípios da igualdade e do acesso a jurisdição ( nesse caso as interpretações da lei não podem ser dissonantes a ponto de beneficiarem uns em detrimento de outros, quando feito de forma objetiva).

Transcrevo recentes acórdãos do Superior Tribunal de Justiça para ilustrar o afirmado acima.

"HABEAS CORPUS. TRAFICO DE ENTORPECENTES. COMETIMENTO NA VIGENCIA DA LEI 6.368/76. ART. 33, § 4', DA LEI 11.343/06. NOVATIO LEGIS IN MELLIUS. MATÉRIA NÃO APRECIADA PELO JUIZZO SENTENCIANTE. LEI NOVA JÁ EM VIGOR AO TEMPO DA CONDENAÇÃO. NULIDADE. REJEIÇÃO PELO TRIBUNAL ORIGINÁRIO. COMBINAÇÃO DE LEIS NO TEMPO. IMPOSSIBILIDADE.

INAPLICABILIDADE AOS FATOS ANTERIORES. 
EMPREGO DE UMA OU OUTRA LEGISLAÇÃO EM SUA INTEGRALIDADE. PERMISSIBILIDADE. PRECEDENTES.COAÇAOILEGAL VERIFICADA.

1. Evidente a nulidade parcial da sentença quando $o$ Juizo singular deixa de se manifestar acerca da possibilidade de incidência, no caso, do redutor inserto no $\S 4^{\circ}$ do art. 33 da Lei n. 11.343/06, que já se encontrava em vigor ao tempo da prolação da condenação.

2.A Quinta Turma deste Superior Tribunal de Justiça vem decidindo pela impossibilidade de combinação das leis no tempo, permitindo a aplicação da nova regra mais benigna, trazida pela Lei 11.343/06, ao crime de narcotráfico cometido na vigência da Lei $n$. 6.368/76, somente se o cálculo da redução for efetuado sobre a pena-base cominada ao delito do art. 33 da Lei $n$. $11.343 / 06$.

3. Ressalva do posicionamento deste Relator, no sentido de que, tratando-se a nova regra prevista no $\$ 4^{\circ}$ do art. 33 da Lei 11.343/06 de norma de caráter preponderamente penal e, sendo mais benéfica, aplicase imediata e retroativamente aos crimes cometidos antes de sua vigência, nos precisos termos do art. $5^{\circ}, X L$, da $C F$, e do art. $2^{\circ}$, parágrafo único, do $C P$, independentemente da fase em que se encontrem, devendo a mitigação incidir sobre a sanção cominada na Lei $6.368 / 76$.

4. Ordem concedida para, cassando o acórdão impugnado, anular em parte a sentença condenatória, determinando que o Juizo da condenação analise a possibilidade de redução da pena do paciente com fulcro no art. 33, $\S 4^{\circ}$, da Lei $n$. 11.343/06, aplicando, se for o caso, em sua integralidade, a legislação que melhor favorecê-lo.

(HC 132.398/SP, Rel. Ministro JORGE MUSSI, QUINTA TURMA, julgado em 23/03/2010, DJe 12/04/2010)".

AGRAVO REGIMENTAL EM HABEAS CORPUS. CONCESSÃO DA ORDEM MEDIANTE DECISÃO MONOCRATICA DO RELATOR. POSSIBILIDADE. PRECEDENTES.

COMBINAÇÃO DE LEIS PENAIS FAVORAVEIS AO RÉU. 33, \& 4 $4^{\circ}$ DA LEI 11.343/06 E ARTIGO 12 DA LEI 6.368/76. VIABILIDADE. AGRAVO REGIMENTAL AO 


\section{QUALSE NEGA PROVIMENTO.}

1. Ambas as Turmas que integram a $3^{a}$ Seção deste Superior Tribunal de Justiça se tem manifestado no sentido de ser possivel a concessão de ordem de habeas corpus mediante decisão monocrática. Precedentes.

2. A Sexta Turma desta Corte Superior de Justiça, em caso análogo ao dos presentes autos, reafirmou o entendimento no sentido de ser possivel a combinação do artigo 33, § $4^{\circ}$, da Lei 11.343/06 com o artigo 12 da Lei 6.368/76.

3. Agravo regimental ao qual se nega provimento.

(AgRg no HC 119.429/SP, Rel. Ministro CELSO LIMONGI DESEMBARGADOR CONVOCADO DO TJ/SP), SEXTA TURMA, julgado em 02/03/2010, DJe 22/03/2010)

$\mathrm{Na}$ doutrina a possibilidade de combinação de leis em direito penal, é também um tema tormentoso. Luiz Regis Prado e Cezar Roberto Bitencourt", afirmam “...não há óbice algum à admissão da simbiose ou combinação normativa em prol do agente.

Contudo discordo da orientação retro.

A possibilidade do magistrado fazer combinação de leis, tirando parte da norma que favoreça o réu, criando uma terceira norma é um verdadeiro cheque em branco, para a prática de excessos, havendo usurpação de função típica de um dos Poderes, no caso, o Legislativo.

Na doutrina, opinam contra a possibilidade de combinação de leis Nélson Hungria, Heleno Fragoso e Aníbal Bruno, Paulo José da Costa Júnior José Henrique Pierangelli e outros.

Foi feliz o legislador ao inserir a proibição de combinação de leis no art. $2^{\circ}, \S 2^{\circ}$ do Código Penal Militar.

Nessa linha, expôs posição contrária na combinação de normas, o renomado doutrinador Guilherme de Sousa Nucci ${ }^{5}$, verbis:

Realmente, se houvesse permissão para a combinação de leis, colocar-se-ia em risco a própria legalidade, pois o magistrado estaria criando norma inexistente, por

\footnotetext{
'PRADO, Luiz Regis, BITTENCOURT, Cezar Roberto. Código penal anotado e legislação complementar. São Paulo: Revista dos Tribunais, 1997.p. 153.

NUCCI, Guilherme de Sousa. Manual de direito penal: parte especial. 6 ed. São Paulo: Revista dos Tribunais, 2009. p. 105.
} 
mais que se queira dizer tratar-se de mera integração de leis. Ora, a referida integração não passa do processo criador de uma outra lei, diferente das que lhe serviram de fonte. E quando se diz que o art. $2^{\circ}$, parágrafo único do CP, autoriza a aplicação da lei posterior benéfica que " de qualquer modo favorecer o agente" não está legitimando o magistrado a recortar pedaços da norma $e$ aplicá-la em formação de uma outra totalmente inédita. Quer dizer simplesmente que uma lei penal nova mais benéfica, em qualquer ponto que seja, merece retroagir para favorecer o réu. A previsão do mencionado parágrafo único é uma cautela positiva, para que não se deixe de aplicar lei penal benéfica sob a assertiva de que não se cuida da pena propriamente dita ou da descrição da conduta típica. Há detalhes secundários que podem ser alterados na lei penal, merecedores de aplicação imediata. Exemplificando: se uma nova lei permite sursis sem o cumprimento de qualquer condição, embora não diga respeito ao tipo penal incriminador e ainda que o condenado esteja em liberdade, é um modo de favorecê-lo, logo, deve ser aplicada, eliminando-se as condições anteriormente fixadas.

No Supremo Tribunal Federal, a posição que prevalece é de que não é possível a combinação de leis, desde a decisão plenária proferida no RCrim 1381.

PENAL. HABEAS CORPUS. CRIME DE TRÁFICO ILÍCITO DE ENTORPECENTES COMETIDO NA VIGÊNCIA DA LEI $6.368 / 76$. APLICAÇÃO RETROATIVA DO PARÁGRAFO $4^{\circ}$ DO ART. 33 DA LEI $11.343 / 06$. INADMISSIBILIDADE. COMBINAÇÃO DE LEIS. NECESSIDADE DE REVOLVIMENTO DO CONJUNTO FÁTICOPROBATÓRIO. WRIT DENEGADO. 1. A nova lei de drogas (Lei 11.343/2006), que revogou as Leis $6.368 / 1976$ e 10.409/2002, estabelece, em seu artigo 33, pena mínima de reclusão de 5 (cinco) anos, ou seja, tratou de modo bem mais severo o crime de tráfico de entorpecentes que a antiga lei, que estabelecia como pena mínima 3 (três) anos. 2. Contudo, no $\S 4^{\circ}$ do art. 33, a nova lei trouxe uma causa especial de diminuição de pena de $1 / 6$ (um sexto) a $2 / 3$ (dois terços), concedida ao agente que cumpre os seguintes requisitos: ser primário, 
ter bons antecedentes, não se dedicar às atividades criminosas e nem integrar organização criminosa. Nesse aspecto, portanto, a lei nova em relação ao agente que se enquadra nos requisitos supramencionados foi mais benéfica (lex mitior). 3. O Supremo Tribunal Federal tem entendimento fixado no sentido de que não é possível a combinação de leis no tempo. Entende a Suprema Corte que, agindo assim, estaria criando uma terceira lei (lex tertia). 4. Com efeito, extrair alguns dispositivos, de forma isolada, de um diploma legal, e outro dispositivo de outro diploma legal implica alterar por completo o seu espírito normativo, criando um conteúdo diverso do previamente estabelecido pelo legislador. 5. Consoante já decidiu esta Suprema Corte, "não é possível aplicar a causa de diminuição prevista no art. $33, \S 4^{\circ}$, da Lei $11.343 / 06$ à pena-base relativa à condenação por crime cometido na vigência da Lei $6.368 / 76$, sob pena de se estar criando uma nova lei que conteria o mais benéfico dessas legislações." (HC 94.848/MS, Rel. Min. Cármem Lúcia, DJe 089, 15.05.2009). 6. Por fim, vale ressaltar que, para aplicação do $\S 4^{\circ}$ do art. 33 da Lei 11.343/06, o agente deve preencher os seguintes requisitos: ser primário, ter bons antecedentes, não se dedicar às atividades criminosas e nem integrar organização criminosa. 7. No caso concreto, por força dos estreitos limites do habeas corpus, não há como verificar se o paciente, efetivamente, não se dedicava às atividades criminosas, nem integrava organização criminosa. 8 . Esta Corte tem orientação pacífica no sentido da incompatibilidade do habeas corpus quando houver necessidade de apurado reexame de fatos e provas (HC 89.877/ES, rel. Min. Eros Grau, DJ 15.12.2006). 9. Writ denegado.

(HC 98766, Relator(a): Min. ELLEN GRACIE, Segunda Turma, julgado em 15/12/2009, DJe-040 DIVULG 04-03-2010 PUBLIC 05-03-2010 EMENT VOL-02392-02 PP-00382)"

EMENTA: HABEAS CORPUS. DOSIMETRIA PENAL. QUANTIDADE DE ENTORPECENTES. LEGITIMIDADE PARA ELEVAÇÃO DA PENA BASE. APLICAÇÃO PARCIAL DE LEI POSTERIOR, NA PARTE EM QUE BENEFICIA O RÉU. INVIABILIDADE. ORDEM DENEGADA. 1. É 
legítimo o aumento da pena base com fundamento na elevada quantidade de entorpecente encontrada em poder da paciente. 2 . Não é permitida, nem mesmo para beneficiar o réu, a combinação de dispositivos de leis diversas, criando uma terceira norma não estabelecida pelo legislador, sob pena de violação aos princípios da legalidade, da anterioridade da lei penal (art. $1^{\circ}$ do Código Penal) e da separação de poderes. 3. Ordem denegada. (HC 96844, Relator(a): Min. JOAQUIM BARBOSA, Segunda Turma, julgado em 04/12/2009, DJe-022 DIVULG 04-02-2010 PUBLIC 05-02-2010 EMENT VOL-02388-01 PP-00125).

A impossibilidade de combinação das leis assegura e protege um dos princípios mais caros ao Direito Penal moderno e garantista: "o princípio da legalidade", sendo certo que o juiz não pode se intrometer nas atividades do legislativo, e atue como legislador positivo no exame da aplicação de duas leis ao caso concreto, criando um terceiro gênero de lei não promulgada pelos órgãos competentes, ferindo de morte a tão decantada segurança jurídica, que na lapidar lição de San Tiago Dantas ${ }^{6}$.

Muita gente diz que a finalidade do Direito é produzir a justiça, mas tão importante é a produção de justiça como a produção da segurança, e numerosos institutos $e$ normas juridicas nós não compreenderíamos se a única finalidade do Direito fosse fazer justiça. É que ele quer fazer justiça mas quer fazer também segurança. "É bom que se diga, mais uma vez, que ninguém está autorizado a ler na Constituição o que lá não está escrito, prática muito a gosto dos neo/e ou pós-positivistas, gente que reescreve a Constituição na toada de seus humores. Permito-me afirmar, ademais que o Poder Judiciário não está autorizado a substituir a ética da legalidade por qualquer outra?."

Assim, como a positividade taxativa é princípio maior no Direito Penal, a Segurança Jurídica é um dos primados do Estado Democrático de Direito, uma

${ }^{6}$ DANTAS, San Tiago. Programa de direito civil: parte geral. 3 ed. Rio de Janeiro: Forense, 2001. p. 16.

GRAU, Eros Roberto. Sobre a Prestação Jurisdicional e Direito Penal. São Paulo: Malheiros, 2010, página 112 . 
vez que a aplicação dissonante de entendimentos sobre um mesmo tema, e ainda o que é mais grave, sobre a liberdade, gera um caos no sistema normativo e na crença das instituições judiciárias, faz-se necessário aplicar a sentença penal sem a possibilidade de combinação de leis, utilizando-se da lei mais benéfica na ponderação dos valores que estiverem em jogo, que melhor beneficiem o réu.

\section{REFERÊNCIAS BIBLIOGRÁFICAS:}

BASTOS, Celso Ribeiro. Hermenêutica e Interpretação Constitucional. São Paulo: Editora Celso Bastos Editor, 1997.

COSTA, Paulo José Júnior. Direito Penal Objetivo. Rio de Janeiro: Forense Universitária, $3^{\circ}$ edição, 2003.

DANTAS, San Tiago Dantas. Programa de Direito Civil - Parte Geral. Rio de Janeiro: Editora Forense, $3^{\text {a }}$ Edição, 2001.

FRANÇA, Celso Limongi. Hermenêutica Jurídica. São Paulo: Editora Saraiva, 1997.

GRAU, Eros Roberto. Sobre a Prestação Jurisdicional e Direito Penal. São Paulo: Editora Malheiros, 2010.

MAXIMILIANO, Carlos . Hermenêutica e Aplicação do Direito. Rio de Janeiro: Editora Forense 14 edição, 1994.

NUCCI, Guilherme de Sousa. Manual de Direito Penal. Parte Geral. Parte Especial. São Paulo: Editora Revista dos Tribunais, $6^{\circ}$ edição, 2009.

BITTENCOURT, Prado, Luiz Regis Prado e Cezar Roberto. Código Penal Anotado e Legislação Complementar. São Paulo: Editora Revista dos Tribunais, 1997..

TOLEDO, Francisco de Assis. Princípios Básicos de Direito Penal. São Paulo: Editora Saraiva, $4^{\mathrm{a}}$ edição, 1991. 